\title{
REVIEW
}

\section{Characterizing Research About Interprofessional Education Within Pharmacy}

\author{
Amanda A. Olsen, PhD, ${ }^{a}$ Carly P. Lupton-Smith, ${ }^{b}$ Philip T. Rodgers, PharmD, ${ }^{c}$ Jacqueline E. McLaughlin, $\mathrm{PhD}^{\mathrm{c}}$ \\ ${ }^{a}$ University of Texas-Arlington, College of Education, Arlington, Texas \\ ${ }^{\mathrm{b}}$ Johns Hopkins University, Bloomberg School of Public Health, Baltimore, Maryland \\ ${ }^{\mathrm{c}}$ University of North Carolina, UNC Eshelman School of Pharmacy, Chapel Hill, North Carolina
}

Corresponding Author: Jacqueline E. McLaughlin, University of North Carolina, UNC Eshelman School of Pharmacy, 322 Beard Hall, Chapel Hill, NC 27599. Tel: 919-966-4577. Email: Jacqui_mclaughlin@unc.edu

Submitted January 8, 2021; accepted March 8, 2021; ePublished March 2021

\begin{abstract}
Objective. To determine how pharmacy interprofessional education (IPE) has been studied, namely which disciplines have engaged in pharmacy IPE research initiatives, the research methodologies that have been used to study pharmacy IPE, and journals that have published pharmacy IPE studies.

Findings. In the 145 IPE studies included in the review, the authors represented 13 different disciplines $(3.2 \pm 1.5$ disciplines/study). Pharmacy authors most commonly published with co-authors from nursing, medicine, and health management and support and most frequently served as first author and as last author. IPE activities involved 4.0 \pm 1.9 student disciplines with $211.8 \pm 280.1$ students, most commonly involving nursing $(\mathrm{n}=104,71.7 \%)$, medicine $(\mathrm{n}=102$, $70.3 \%)$, and health management and support students $(n=50,34.5 \%)$. Most studies did not include an author from each student discipline involved in the IPE $(\mathrm{n}=88,60.7 \%)$. Further a majority of studies used non-randomized groupings $(\mathrm{n}=103,71.0 \%)$ with quantitative data $(\mathrm{n}=74,51.0 \%)$ and most were published in an interprofessional journal $(\mathrm{n}=65$, $44.8 \%)$ or pharmacy-specific journal $(n=45,31.0 \%)$.
\end{abstract}

Summary. This review summarizes how pharmacy IPE has been studied and highlights opportunities for advancing IPE research and practice.

Keywords: interprofessional education, research methods, scholarship, publishing, authorship

\section{INTRODUCTION}

In 2007, the World Health Organization (WHO) launched its Programme on Interprofessional Education and Collaborative Practice to investigate and advocate for Interprofessional Education (IPE) across the health professions. ${ }^{1}$ "Interprofessional education occurs when students from two or more professions learn about, from, and with each other to enable effective collaboration and improve health outcomes."1 To optimize patient care, educators must strategically organize interprofessional teams that are focused on intentionally equipping students with the skills requisite for success in today's collaborative health care environment. ${ }^{2}$

The importance of IPE in pharmacy has been emphasized by various scholars and organizations, including the Center for the Advancement of Pharmacy Education (CAPE) and the Accreditation Council for Pharmacy Education (ACPE) standards for the entry-level Doctor of Pharmacy degree. ${ }^{3,4}$ Specifically, IPE initiatives have been found to successfully increase knowledge, promote team building, and build problem-based learning skills..$^{5-7}$ Cohen and colleagues, for example, reported that IPE training promoted sustained improvements in knowledge of IPE, understanding the role of other disciplines, and positive attitudes toward the value of teams after training. ${ }^{5}$ The authors of these studies have advocated for the continued implementation of IPE initiatives due to their many positive outcomes. ${ }^{5-7}$

Faced with a substantial and growing number of studies about IPE in pharmacy, several scholars have conducted reviews about various aspects of IPE. These include reviews of IPE assessment tools, ${ }^{8}$ interprofessional distance education, ${ }^{9}$ and pharmacy perspectives towards IPE. ${ }^{10}$ To date, publications have largely focused on what has been studied in IPE (eg, design, implementation, and assessment of IPE), with little attention to how it has been studied (eg, researcher disciplines, research design, dissemination). Since IPE has been shown to improve knowledge and enhance teamwork, it is important to understand how IPE has been studied in pharmacy education. Therefore, the purpose of this review was to characterize research on IPE involving student pharmacists; specifically: 1) which disciplines have engaged in pharmacy IPE research initiatives, 2) which research methodologies have been used to study that IPE, and 3) which journals have published those studies.

\section{METHODS}


The search terms selected for this review were "interprofessional education" AND "student." These search terms were selected to provide the most extensive selection of articles to capture IPE research in all health professions disciplines. The search was conducted in October 2018 using PubMed, SCOPUS, PsycINFO, EMBASE, MEDLINE, and ERIC. PubMed, SCOPUS, EMBASE, and MEDLINE are databases that were used in other IPE reviews, ${ }^{10-12}$ while ERIC and PsycINFO were chosen to find additional education and interdisciplinary articles. The Journal of Interprofessional Care was hand-searched to capture additional articles.

A study was included in this review if it included students from the United States, was published in a peerreviewed journal, contained an IPE opportunity where students engaged, collaborated, participated, and/or exchanged ideas with students from another health profession ${ }^{1}$ and included a pharmacy affiliated author. Studies may have included a pharmacy affiliated author, but not pharmacy students. Authors were categorized using their credentials (PharmD, MD, etc.), their university affiliation, their university biography, and/or their Google Scholar or ResearchGate account. A study was excluded if it was a review (eg, meta-analysis, systematic review, literature review), not peer-reviewed (eg, commentaries, dissertations, book chapters), not written in English, or designed to validate a measure or instrument.

Journal articles were cataloged in Mendeley and uploaded into Covidence (Melbourne, Australia), a software used for article screening, data abstraction, and duplication removal. Adhering to the inclusion and exclusion criteria, an abstract review followed by a full-text review for inclusion were conducted by two independent reviewers. Conflicts were resolved by a third independent reviewer.

After identifying articles for inclusion, data were extracted for the following variables: author discipline; student discipline; analytic technique (ie, quantitative -analyzed numerical data; qualitative - analyzed non-numerical data; and mixed-methods, analyzed both non-numerical and numerical data); participant grouping technique (ie, observational, randomized, and non-randomized); and journal type (ie, IPE or discipline specific journal). Author and student disciplines were classified according to WHO categorizations. ${ }^{1}$ Specifically, pharmacy, nursing, medicine, midwifery, dentistry, physiotherapy, optometry, dietetics, occupational therapy, audiology, environmental health, and physician assistants were classified as "health professionals." Professions in the "health management and support" category included social work and clinical psychology. Occupations in the "health associate professionals" category included professions that complete technical and practical tasks to support diagnoses and treatments (eg, respiratory therapy and medical assistants). ${ }^{1}$ Professions that were not categorized as health professionals by the WHO were placed in the "not health professionals" category, which included educational researchers and statisticians. Authors were categorized using all possible degree holders within those categories, meaning that medicine, for example, included individuals who were medical doctors (MD), doctors of osteopathic medicine (DO), and/or affiliated with a school of medicine.

In a data audit of extracted data from $15 \%$ of the articles, agreement between researchers on categorizations exceeded $95 \%$. Descriptive statistics were used to analyze the variables of interest. Categorical data are presented as number (percent) and continuous data are presented as mean \pm standard deviation (SD).

\section{RESULTS}

As seen in Figure 1, 3,058 studies were imported for screening and 1,518 abstracts were reviewed after removing duplicates, which yielded 680 studies for the full text screening. Of these, 145 met the inclusion criteria and were advanced for analysis.

In the reviewed studies, pharmacy authors collaborated with 12 disciplines: nursing $(\mathrm{n}=73,50.3 \%)$, medicine ( $\mathrm{n}$ $=71,49.0 \%)$, health management and support $(\mathrm{n}=47,32.4 \%)$, not health professionals $(\mathrm{n}=47,32.4 \%)$, physiotherapy $(\mathrm{n}$ $=25,17.2 \%)$, occupational therapy $(\mathrm{n}=16,11.0 \%)$, dentistry $(\mathrm{n}=12,8.3 \%)$, heath associate professionals $(\mathrm{n}=12,8.3 \%)$, physician assistants $(\mathrm{n}=10,6.9 \%)$, dietetics $(\mathrm{n}=9,6.2 \%)$, audiology $(\mathrm{n}=3,2.1 \%)$, and environmental health $(\mathrm{n}=1$, $0.7 \%$; see Table 1). On average, there were $6.1 \pm 2.7$ authors per study and $3.2 \pm 1.5$ author disciplines per study. Authorship collaboration ranged from one discipline per study $(\mathrm{n}=10,6.9 \%)$ to 7 disciplines per study $(\mathrm{n}=3,0.02 \%)$. Most commonly, first authors were from pharmacy $(\mathrm{n}=68,46.9 \%)$, medicine $(\mathrm{n}=27,18.6 \%)$, and nursing $(\mathrm{n}=17$, $11.7 \%)$. Similarly, the most common last authors were from pharmacy $(\mathrm{n}=48,33.1 \%)$, medicine $(\mathrm{n}=29,20.0 \%)$, and nursing $(\mathrm{n}=19,13.1 \%)$.

On average, there were $4.0 \pm 1.9$ student disciplines per study, ranging from 2 to 10 student disciplines. There were $211.8 \pm 280.1$ students per study (range $=7$ to 2,139$)$. Pharmacy students were involved in $141(97.2 \%)$ of the 145 studies that included an author from pharmacy. Other common student disciplines included nursing $(\mathrm{n}=104,71.7 \%)$, medicine $(\mathrm{n}=102,70.3 \%)$, and health management and support $(\mathrm{n}=50,34.5 \%)$. When comparing student and author disciplines, most studies, predominantly from nonpharmacy professions, contained a mismatch, where a student discipline was included in a study without an author from that same discipline $(\mathrm{n}=88,60.7 \%)$.

The research methodologies utilized in the reviewed studies included quantitative $(n=74,51.0 \%)$, mixedmethods $(\mathrm{n}=54,37.2 \%)$, and qualitative $(\mathrm{n}=17,11.7 \%)$ approaches. Of the papers involving quantitative data, a 
majority included inferential statistics $(n=99,77.3 \%)$. Most qualitative methods included inductive coding analysis $(n=$ $65,92.9 \%)$. Further, participants were mostly grouped in a non-randomized fashion $(\mathrm{n}=103,71.0 \%)$. Thirty-seven $(25.5 \%)$ studies used observational groupings and only 5 (3.5\%) studies used random assignment to group participants.

IPE research that included pharmacy authors was most commonly published in 7 interprofessional journals $(\mathrm{n}=$ $65,44.8 \%)$ or in 5 pharmacy-specific journals $(n=45,31.0 \%)$ (Table 2$)$. The most common journals included the Journal of Interprofessional Care $(n=38,26.2 \%)$, Currents in Pharmacy Teaching and Learning $(n=22,15.2 \%)$, the American Journal of Pharmaceutical Education $(\mathrm{n}=19,13.1 \%)$, and the Journal of Interprofessional Education and Practice $(\mathrm{n}=12$, $8.3 \%)$. Several studies were published in discipline-specific journals, such as journals in medicine $(\mathrm{n}=22,15.2 \%)$, nursing $(\mathrm{n}=8,5.5 \%)$, and health management and support $(\mathrm{n}=5,3.4 \%)$. Further, the number of IPE publications including pharmacy authorship increased from 1 study in 2008 to 37 studies in 2018 (Figure 2).

\section{DISCUSSION}

Since the WHO launched its interprofessional initiative in 2007, pharmacy educators have increasingly engaged in IPE and IPE research. The substantial body of IPE literature to-date reflects the critical efforts by health care educators to both prepare aspiring health professionals for team-based care and generate evidence providing insight into these collaborative initiatives. As an extension of previous reviews that emphasized IPE settings and effectiveness, ${ }^{11-13}$ this study specifically explored research strategies used by pharmacy educators to study IPE, including authorship, student involvement, study design, and publication.

The results of this study suggest that authors from pharmacy education have collaborated across a wide range of disciplines to implement, evaluate, and disseminate IPE. Not surprisingly, pharmacy authors most commonly co-authored papers with colleagues from nursing and medicine, as these disciplines may have more students take part in these studies due to proximity and job responsibilities (eg, inpatient medical settings). ${ }^{14}$ Similarly, pharmacy studies most commonly included students from nursing and medicine. There were also more medicine, nursing, and pharmacy students/graduates than any other group of professions, meaning there may be more students around to interact. ${ }^{15-17}$ Further, the logistical barriers related to scheduling IPE activities across health professions schools may be less prevalent for these disciplines given their close working proximity, particularly in experiential settings. ${ }^{18}$ Engaging additional authors and students from other professions may require more arduous efforts to reduce barriers between professions and their trainees.

Pharmacy authors also most commonly served as first author and as last (presumably, senior) author on IPE studies when compared to other professions in this review. Since most journals do not require descriptions of author roles, it was not possible to glean the contributions of each author in this review. Differences between disciplines as it relates to authorship norms can influence authorship order and contributions. As discussed by Minshew and McLaughlin, "it is important to understand how authorship impacts faculty members' ability to be successful within and beyond their disciplines." ${ }^{19}$ For example, a faculty member from one discipline (eg, pharmacy) may have different authorship needs or expectations for promotion than a faculty member from another discipline (eg, not health), resulting in varied authorship practices. Since IPE is inherently collaborative, more work should be done to promote transparency and integrity in authorship practices. Authors should explicate their roles within articles so readers are able to discern the contributions of each individual to the IPE initiative and its related research. ${ }^{19}$ Depending on journal requirements, this could be done within sections of the manuscript (eg, using author initials in the methods section to explicate author roles) or in a separate section immediately preceding the references.

Given the importance of collaboration in IPE, in pharmacy authored publications, the author group should consider including an author representative from each discipline whose students were included. In other words, student disciplines were often included in a study without an author from that same discipline. Since health professionals are trained in a tradition that aligns with the responsibilities of that profession, ${ }^{20,21}$ a study lacking authorship representation may fail to sufficiently address the implications of IPE outcomes for a discipline specifically or for health care broadly. It leaves some question as to whether the IPE activity adequately addressed and discussed the needs of the students from the profession without the contribution of an author from the same profession. More work is needed to understand why these mismatches occurred and how they may influence the design, evaluation, and interpretation of IPE involving pharmacy.

Nearly half of the studies in this review utilized qualitative data, which was surprising given that the pharmacy and pharmaceutical sciences, especially bench science, are grounded within quantitative methods. This suggests that research and analytic designs used in this study may not follow pharmacy research norms.. Further, very few studies in this review used experimental design or random assignment, which is generally considered the most rigorous design for making causal claims about effectiveness. ${ }^{22}$ While random assignment can enable causal conclusions to be drawn, randomization can be difficult to implement in educational settings and may be considered unethical if only some students are randomized into an educational condition that may likely be beneficial. ${ }^{23}$ As noted by Harpe, "In the current context of the ongoing debate surrounding causality in educational scholarship, the use of appropriate study designs and analytical 
approaches is of utmost importance given the need to generate evidence surrounding the effectiveness of various educational activities and an increasing focus on examining factors that may influence student-or program-level performance. "22 Study designs each have their own advantages and disadvantages with respect to the strength of causal conclusions, and the lack of random assignment used in IPE pharmacy studies raises some question as to the appropriateness of causal claims about IPE. In addition, the use of qualitative data and observational design may indicate that the qualitative aspects of IPE are better understood than other educational interventions or curricula.

The IPE studies in this review were published in a variety of journals. Although most were published in IPE- or pharmacy-specific journals, many were published in journals belonging to other professions (eg, journals for medicine, nursing, and health management and support). It is important to understand where IPE research is being published, as journals often target specific audiences and may engage the audience with discipline-specific lenses. Pharmacy educators may not realize that IPE research is being published in medical or nursing journals, or may not think to actively search journals from other disciplines for IPE research involving pharmacy students. Furthermore, this review identified 7 unique IPE-specific journals in which these pharmacy-authored studies were published. With IPE research being published through so many different journals, it may become difficult to maintain awareness and become deeply engaged with this line of research. We recommend using advanced search strategies such as citation mapping and consulting with librarians who are trained experts in finding appropriate literature.

There were several limitations to this study. First, this review did not assess the content, quality or rigor of each study, since our aim was to determine who engaged in IPE research and how they engaged. Second, even though our search terms were broad and comprehensive, it is possible we missed relevant articles. Third, there may be articles where different health professions disciplines collaborated without explicitly using the term "interprofessional education."

Despite these limitations, this study is an important step toward understanding IPE and identifying potential gaps or anomalies in IPE research that might inform IPE research moving forward. Pharmacy educators may need to consider additional authors, student disciplines, research designs, and dissemination strategies to address gaps in pharmacy IPE effectiveness, utility, and acceptability. Further research should explore the impact and utility of various research practices in IPE, how IPE research is incentivized and operationalized (eg, authorship), and how these practices influence the extent to which we understand the impact of IPE on learners. Promoting the use, evaluation, and dissemination of IPE initiatives, and improving transparency in IPE research, is imperative for advancing collaborative care models within a rapidly evolving health care system.

\section{CONCLUSIONS}

IPE research can elucidate strategies for promoting the skills students must develop for success within a rapidly evolving and highly collaborative health care system. Since the WHO declared IPE a priority in 2007, pharmacists have increased their engagement in IPE research as indicated by authorship order. However, apparent mismatches in author and student disciplines and varied publication practices raise some questions about IPE research practice. In light of this study, pharmacy educators must pursue IPE research that is inclusive and accommodating of scholars from various professions, fosters collaboration between traditional and emerging health professions, and positions students for success within a collaborative health care environment.

\section{ACNKOWLEDGEMENTS}

The authors would like to acknowledge Joseph Yi for data extraction support.

Disclosure: Data from this manuscript were presented as part of a poster at the 2019 American College of Clinical Pharmacists annual meeting.

\section{REFERENCES}

1. World Health Organization. Framework for action on interprofessional education and collaborative practice. World Health Organization. Published 2010. Accessed July 10, 2019.

2. Simko LC, Rhodes DC, McGinnis KA, Fiedor J. Students' perspectives on interprofessional teamwork before and after an interprofessional pain education course. Am J Pharm Educ. 2017;81(6):104. https://doi.org/10.5688/ajpe816104.

3. Accreditation standards and key elements for the professional program in pharmacy leading to the doctor of pharmacy degree, 2016. Accreditation Council for Pharmacy Education. Chicago, IL. https://www.acpeaccredit.org/pdf/Standards2016FINAL.pdf. Accessed July 9, 2018.

4. Medina MS, Plaza CM, Stowe CD, et al. Center for the Advancement of Pharmacy Education 2013 educational outcomes. Am J Pharm Educ. 2013;77(8):162. https://doi.org/10.5688/ajpe778162 
5. Cohen EV, Hagestuen R, Gonázlez-Ramos G, et al. Interprofessional education increases knowledge, promotes team building, and changes practice in the care of Parkinson's disease. Parkinsonism Relat Disord. 2016;22:21-7. https://doi.org/10.1016/j.parkreldis.2015.11.001

6. Cox M, Cuff P, Brandt B, Reeves S, Zierler B. Measuring the impact of interprofessional education on collaborative practice and patient outcomes. J Interprof Care. 2016;30(1):1-3.

https://doi.org/10.3109/13561820.2015.1111052

7. Lehrer MD, Murray S, Benzar R, et al. Peer-led problem-based learning in interprofessional education of health professions students. Med Educ Online. 2015;20(1):28851. https://doi.org/10.3402/meo.v20.28851

8. Shrader S, Farland MZ, Danielson J, Sicat B, Umland EM. A systematic review of assessment tools measuring interprofessional education outcomes relevant to pharmacy education. Am J Pharm Educ. 2017;81(6):119. https://doi.org/10.5688/ajpe816119

9. McCutcheon LRM, Alzghari SK, Lee YR, Long WG, Marquez R. Interprofessional education and distance education: A review and appraisal of the current literature. Curr Pharm Teach Learn. 2017;9(4):729-736. https://doi.org/10.1016/j.cptl.2017.03.011

10. El-Awaisi A, Joseph S, El Hajj MS, Diack L. A comprehensive systematic review of pharmacy perspectives on interprofessional education and collaborative practice. Res Social Adm Pharm. 2018;14(10):863-882. https://doi.org/10.1016/j.sapharm.2017.11.001

11. Olson R, Bialocerkowski A. Interprofessional education in allied health: A systematic review. Med Educ. 2014;48(3):236-46. https://doi.org/10.1111/medu.12290

12. Reeves S, Zwarenstein M, Goldman J, Barr H, Freeth D, Koppel I, Hammick M. The effectiveness of interprofessional education: Key findings from a new systematic review. J Interprof Care. 2010;24(3):230-241. https://doi.org/10.3109/13561820903163405

13. Remington TL, Foulk MA, Williams BC. Evaluation of evidence for interprofessioanal education. Am J Pharm Educ. 2006;70(3):66. https://dx.doi.org/10.5688\%2Faj700366

14. Bell HT, Granas AG, Enmarker I, Omli R, Steinsbekk A. Nurses' and pharmacists' learning experiences from participating in interprofessional medication reviews for elderly in primary health care: A qualitative study. BMC Fam Pract. 2017;18(30). https://doi.org/10.1186/s12875-017-0598-0

15. Association of American Medical Colleges. Medical Education Facts. https://www.aamc.org/datareports/students-residents/report/facts. Accessed October 20, 2020.

16. American Association of Colleges of Nursing. Your nursing career: A look at the facts. https://www.aacnnursing.org/Students/Your-Nursing-Career-A-Look-at-the-Facts. Accessed October 20, 2020.

17. American Association of Colleges of Pharmacy. Profile of pharmacy Students: Fall 2019. https://www.aacp.org/sites/default/files/2020-05/fall-2019-ppsintroduction.pdf\#: : :text=The\%20AACP\%20institutional\%20research\%20data,6\%2C000\%20individuals\%20purs uing\%20graduate\%20study. Accessed October 20, 2020.

18. Lawlis TR, Anson J, Greenfield D. Barriers and enablers that influence sustainable interprofessional education: A literature review. J Interprof Care. 2014;28(4):305-310. https://doi.org/10.3109/13561820.2014.895977

19. Minshew LM, McLaughlin JE. Authorship considerations for publishing in pharmacy education journals. Am J Pharm Educ. 2019;83(6):7463. https://dx.doi.org/10.5688\%2Fajpe7463

20. Brazeau GA, Meyer SM, Belsey, M, Bednarczyk E.M., Bilic S, Bullock J, DeLander GE, Fiese EF, Giroux SL, McNatty D, Nemire R, Prescott WA, Traynor A. Preparing pharmacy graduates for traditional and emerging career opportunities. Am J Pharm Educ. 2009;73(8):157. https://dx.doi.org/10.5688\%2Faj7308157

21. Martin C. Reconstructing a lost tradition: The philosophy of medical education in an age of reform. Med Educ. 2012;47(1):33-39. https://doi.org/10.1111/j.1365-2923.2012.04262.x

22. Harpe SE. Design, analysis, and conclusions: Telling a consistent causal story. Pharm Teach Learn. 2017;9(1):121-136. https://doi.org/10.1016/j.cptl.2016.09.001

23. Hariton E, \& Locascio JJ. Randomised controlled trials - the gold standard for effectiveness research. BJOG. 2018;125(13):1716. https://dx.doi.org/10.1111\%2F1471-0528.15199 
Table 1. Characteristics of IPE Studies with Authors from Pharmacy Schools Published between 2008-2018 $(n=145)$, by Profession

\begin{tabular}{|c|c|c|c|c|}
\hline Profession & $\begin{array}{l}\text { Studies Authored }^{\wedge} \\
\mathbf{N}(\%)\end{array}$ & $\begin{array}{l}\text { Studies as First } \\
\text { Author, Total } \\
\text { N }(\%)\end{array}$ & $\begin{array}{l}\text { Studies as Last } \\
\text { Author, Total } \\
\text { N }(\%)\end{array}$ & $\begin{array}{l}\text { Student } \\
\text { Participants^ } \\
\text { N }(\%)\end{array}$ \\
\hline Pharmacy & $145(100.0 \%)$ & $68(46.9 \%)$ & $48(33.1 \%)$ & $141(97.2 \%)$ \\
\hline Nursing & $73(50.3 \%)$ & $17(11.7 \%)$ & $19(13.1 \%)$ & $104(71.7 \%)$ \\
\hline Medicine & $71(49.0 \%)$ & $27(18.6 \%)$ & $29(20.0 \%)$ & $102(70.3 \%)$ \\
\hline $\begin{array}{l}\text { Health Management and } \\
\text { Support* }\end{array}$ & $47(32.4 \%)$ & $11(7.6 \%)$ & $12(8.3 \%)$ & $50(34.5 \%)$ \\
\hline Not Health* & $47(32.4 \%)$ & $9(6.2 \%)$ & $20(13.8 \%)$ & $12(8.3 \%)$ \\
\hline Physiotherapy & $25(17.2 \%)$ & $4(2.8 \%)$ & $5(3.5 \%)$ & $42(29.0 \%)$ \\
\hline Occupational Therapy & $16(11.0 \%)$ & $4(2.8 \%)$ & $2(1.4 \%)$ & $30(20.7 \%)$ \\
\hline Dentistry & $12(8.3 \%)$ & $0(0 \%)$ & $3(2.1 \%)$ & $31(21.4 \%)$ \\
\hline $\begin{array}{l}\text { Health Associate } \\
\text { Professionals }\end{array}$ & $12(8.3 \%)$ & $3(2.1 \%)$ & $2(1.4 \%)$ & $20(13.8 \%)$ \\
\hline Physician Assistant & $10(6.9 \%)$ & $0(0 \%)$ & $2(1.4 \%)$ & $21(14.5 \%)$ \\
\hline Dietetics & $9(6 . \%)$ & $2(1.4 \%)$ & $2(1.4 \%)$ & $13(9.0 \%)$ \\
\hline Audiology & $3(2.1 \%)$ & $0(0 \%)$ & $0(0 \%)$ & $11(7.6 \%)$ \\
\hline Environmental Health & $1(0.7 \%)$ & $0(0 \%)$ & $0(0 \%)$ & $0(0 \%)$ \\
\hline Midwifery & $0(0 \%)$ & $0(0 \%)$ & $0(0 \%)$ & $1(0.69 \%)$ \\
\hline Optometry & $0(0 \%)$ & $0(0 \%)$ & $0(0 \%)$ & $2(1.4 \%)$ \\
\hline
\end{tabular}

*"Health Management and Support" refers to supporting professions (eg, social work, clinical psychology); "Not Health" includes non-health fields (eg, educational researchers, statisticians); and "Health Associate Professionals" refers to health professions that perform technical and practical tasks to support diagnoses and treatment (eg, respiratory therapists and medical assistants)

${ }^{\wedge}$ Studies may include individuals from multiple professions, therefore percentages may sum to exceed $100 \%$

Table 2. Characteristics of Journals $(n=38)$ Publishing IPE Studies with Authors from Pharmacy Schools $(n=145)$

\begin{tabular}{lll}
\hline Profession & $\begin{array}{l}\text { Journal Focus } \\
\mathbf{n}(\boldsymbol{\%})\end{array}$ & $\begin{array}{l}\text { Journal Focus, by Study } \\
\mathbf{n}(\boldsymbol{\%})\end{array}$ \\
\hline Interprofessional & $7(18.4 \%)$ & $65(44.8 \%)$ \\
\hline Pharmacy & $5(13.2 \%)$ & $45(31.0 \%)$ \\
Nursing & $6(15.8 \%)$ & $8(5.5 \%)$ \\
Medicine & $12(31.6 \%)$ & $15(10.3 \%)$ \\
Health Management and & $4(10.5 \%)$ & $5(3.45 \%)$ \\
Support* & $3(7.9 \%)$ & $6(4.1 \%)$ \\
Specialized Medicine & $1(2.6 \%)$ & $1(0.7 \%)$ \\
Dietetics & $\mathbf{3 8}$ & $\mathbf{1 4 5}$ \\
\hline Total & &
\end{tabular}


Figure 1. Study Selection Diagram

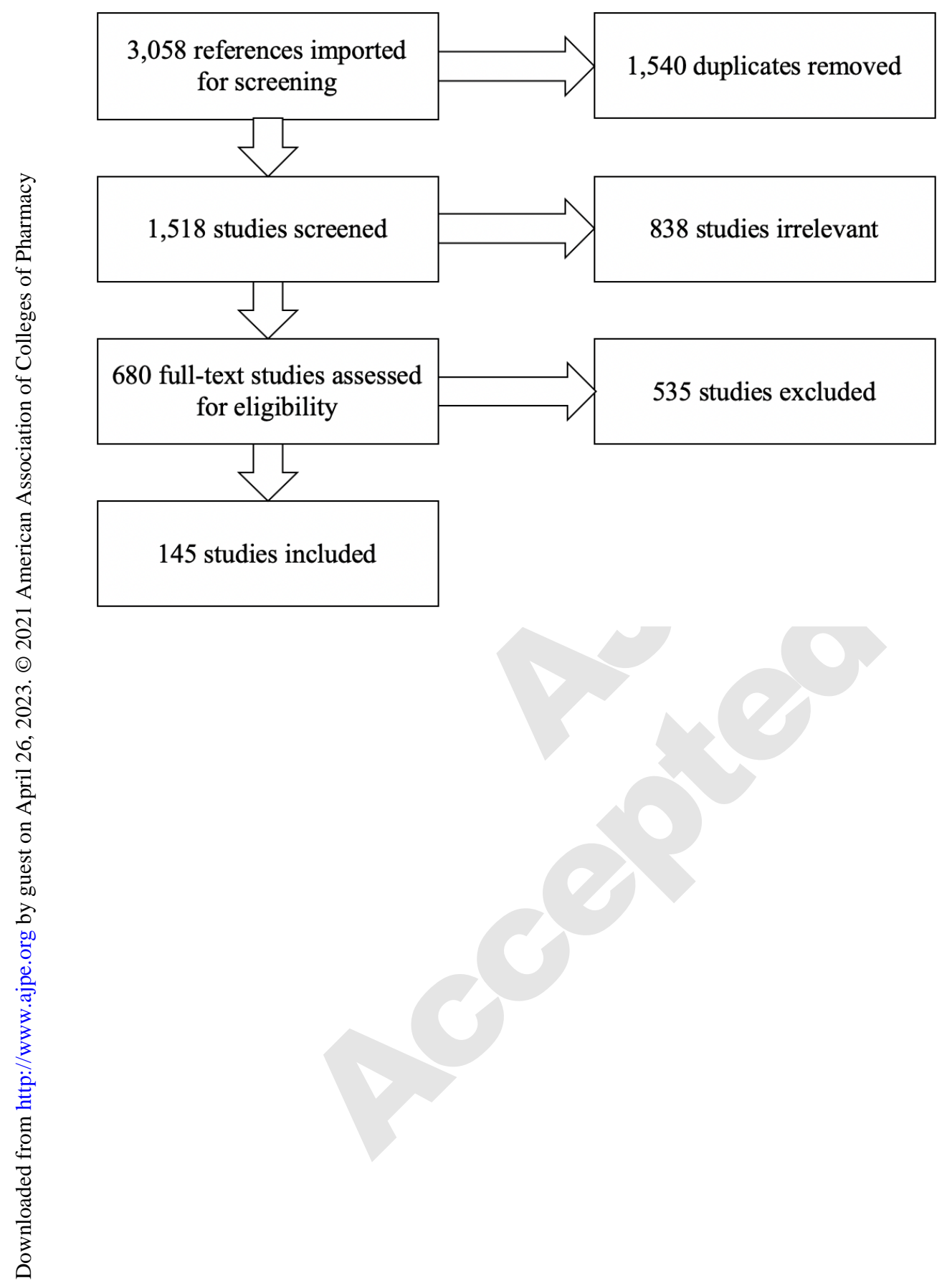

